\title{
Analysis on the Strategy of Urban Space Expansion and Land Resource Management
}

\author{
Rahna Abubaker Kovoor ${ }^{1}$, Dr. Sumam Panjikaran² \\ ${ }^{1}$ Department of Architecture, TKM College of Engineering, Kollam, India \\ rahna.abubaker@gmail.com \\ ${ }^{2}$ Professor, Department of Architecture, TKM College of Engineering, Kollam, India \\ sumampanjikaran@gmail.com
}

\begin{abstract}
One of the major reasons for the rural - urban continuum type of settlement in Kerala is urban sprawl. The issues due to sprawl in Kerala include negative growth rate of core areas, higher growth rate of fringes, uncontainable urban spread, under utilized land pockets in the core, degradation of core, dilution of rural and urban economy and many others. As a result, it is important to tackle the problem of urban sprawl using appropriate planning mechanisms. The study proposes urban compaction as a strategy to curb urban sprawl in the study area of Kollam Municipal Corporation. The study area is selected based on its rapid urban spread and the high population density, which can provide ease to the compaction process. The study area is analyzed in detail for the trends in population growth and distribution. With the help of this analysis and sustainability goals, certain parameters are selected to measure the suitability of wards for urban compaction. Composite Functionality Index method is used for this purpose and the wards are grouped into first order, second order, third order and fourth order settlements. Then, strategies are proposed for the various order of settlements based on the issues faced by each of them.
\end{abstract}

Keywords: Urban Sprawl, urban compaction, composite functionality index, settlement hierarchy

\section{Introduction}

According to the 2011 census, there is a rapid increase in urban population in Kerala from $25.96 \%$ to $47.72 \%$ from 2001 to 2011. Kerala is the second most urbanized state, with a percentage increase of 83.20 of urban population in 2011, when compared to 2001. The State Urbanization Report of Kerala - 2012 had identified the reason for such an increase as the urban spread of existing urban areas in Kerala, rather than change in economy of the state.

Also, three of the Urban Agglomerations in Kerala, have occupied positions among 10 of the world's fastest growing cities according to the Economist Intelligence Unit (EIU) survey (2015 - 2020). Malappuram, Kozhikode and Kollam, occupy the first, fourth and the tenth positions in the list respectively. While Malappuram shows a 44.1 per cent change in urban population growth, Kozhikode has a change of 34.5 per cent. Kollam, the third city, has an urbanization growth rate of 31.1 per cent. Thrissur also occupies the $13^{\text {th }}$ position in the list. According to the newspapers 'The Indian Express' and the 'Times of India' the main reason for the ranking of these cities is rapid urbanisation, due to the inclusion of new areas in the Urban Agglomeration limits

\section{Need of the Study}

In order to prove the need of the study, statements from various planning documents have been quoted:

- Kerala Perspective Plan 2030 - Compact city as an ideal policy for urban revitalization and the formation of new cities in the state. [1]

- State Urbanization Report of Kerala 2012 - The urban vision of the State is 'Revitalised urban areas of compact urban form, distributed in a balanced and orderly manner in the entire Kerala, that perform urban functions complimentary to the rural hinterland and act as engines of development'. [2]

- Master Plan for Kozhikode Urban Area 2035 - The Master - plan for Kozhikode Urban Area (2015 - 2035) is endeavoured along these lines (urban vision), and braces up to enhance the quality of life within the urban area, while proposing measures to strengthen its economic base. [3]

- Vision of Draft Report of Master Plan of Trivandrum Corporation Area - 2031 - A Green City of various functional aspects with an economically lively compact urban form possessing global standards in basic facilities and services. [4]

The above mentioned planning reports reflect the importance of the concept of 'Compact City Planning' in Kerala. 'Urban Compaction' is one of the main principles of Compact City Planning. As a result, the study is taken up to propose 'Urban Comp

\section{What is Urban Sprawl?}

Urban sprawl can be defined as urban development with low - density housing, both residential and commercial, segregated land - use, high level of automobile use combined with lack of public transport, which is in high demand for land [5]. The uncontrolled and disproportionate expansion of an urban area into the surrounding countryside, forming low - density, poorly planned patterns of development. Common in both high - income and low - income countries, urban sprawl is characterized by a scattered population living in separate residential areas, with long blocks and poor access, often over dependent on motorized transport and missing well - defined hubs of commercial activity [6]. 


\section{What is Urban Compaction?}

Urban compaction is a sub concept of compact city planning which promotes high density, mixed land use and intensification of urban areas, against urban sprawl.

As of now, the most widely quoted definition of compaction is that of Burgess Rod "Compaction means to increase built area and residential population densities, to intensify urban economic, social and cultural activities and to manipulate urban size, form and structure and settlement systems in pursuit of the environmental, social and global sustainability benefits derived from the concentration of urban functions." [7]

\section{Study Area}

Kollam Municipal Corporation Area is selected as the study, mainly due to the 10nth position of Kollam Urban Agglomeration in the list of World's most growing cities prepared on the basis of EIU Survey conducted from 2015 to 2020. Malappuram and Kozhikode were the other urban agglomerations of Kerala, preceding the rank of Kollam in terms of urban growth, in the list.

Since, urban compaction strategy would be more applicable in a municipal corporation limit, Malappuram was excluded as the study area. Also, urban compaction principles can be effectively executed in denser areas, which increased the possibility of Kollam Municipal Corporation to be considered as the study area, over Kozhikode Municipal Corporation. The population density of Kollam Municipal Corporation Area is 6090 whereas that of Kozhikode Municipal Corporation Area is 5149, according to 2011 Census

Kollam Municipal Corporation is the second densest Corporation Area in Kerala. Also, Kollam Urban Agglomeration grew from one municipal corporation in 2001 to one Municipal Corporation, 2 municipalities, 22 Panchayaths and parts of 2 Panchayaths in 2011. There is an increase of $130 \%$ in the population of Kollam UA, while a decrease of $4 \%$ was observed in the population of the original ST.

The study area comprises of an area of 57.31 square kilometres centred at Kollam, with about ward 52 divisions and a population of 3.49 lakhs.

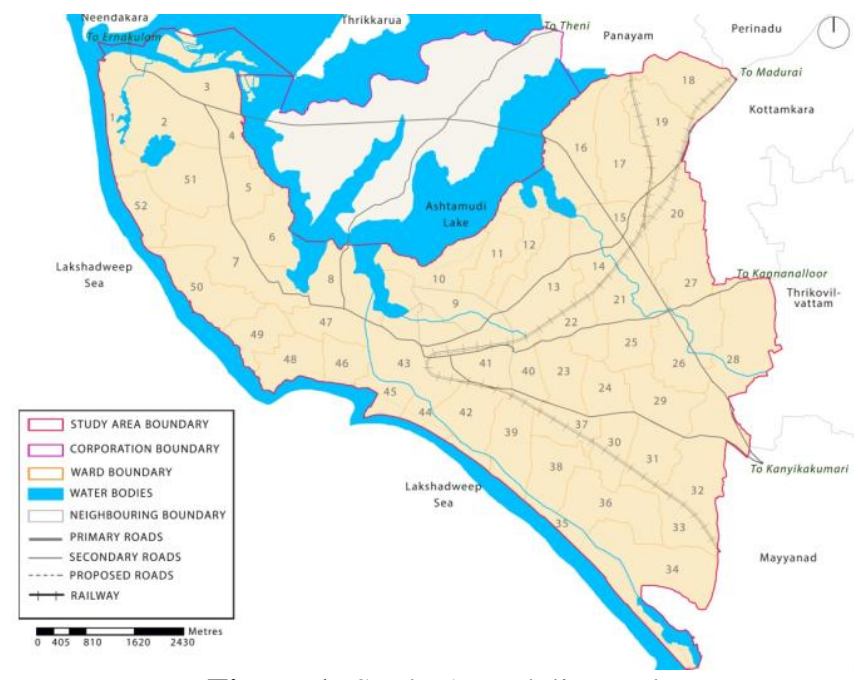

Figure 1: Study Area delineated

\section{Aim and Objectives}

The aim is to formulate guidelines for urban compaction in Kollam Corporation with due consideration to sustainability.

The objectives are:

- To identify the trends in distribution and growth of population in Kollam Corporation with respect to occupation, housing density, infrastructure facilities and environmental factors.

- To determine the maximum holding capacity of the study area.

- To identify the wards which can be subjected to urban compaction, using selected indicators based on sustainability and identified population trends in the study area.

- To provide strategies for realization of urban compaction in the study area.

\section{Methodology}

The methodology for achieving each objective is described. In order to achieve objective 1, the following are to be done:

- Comparison of population densities of different year

- Study of distribution of occupational pattern

- Study and comparison of land uses of different years

- Study of the housing settlement pattern

- Study of Transportation facilities

- Study of Social Infrastructure

- Study of Physical Infrastructure

- Study of Environmental factors

In order to achieve the second objective, the commodity or service which is in the shortest supply should be identified.

For the next objective, Composite Functional Index method is to be utilized to find the hierarchy of settlements for urban compaction. Literature review and case studies are to be referred for the proposal of strategies according to the last objective. 


\subsection{An approach to calculate CFI (Literature Reviewed)} [17]

Service centres and functions are identified based on the characteristics of the area. The weightage of each identified function is calculated by the formula:

$\mathrm{Wi}=\mathrm{N} / \mathrm{Fi}$,

Where $\mathrm{Wi}$ is the weightage of ith function,

$\mathrm{N}$ is the total number of settlements,

$\mathrm{Fi}$ is the number of settlements having that function.

Then Functional Centrality Index of each centre is calculated by the formula:

$F C I=\sum_{i}^{n} \frac{W i j}{W} \times 100$

Where FCI is the functional centrality index,

Wij is the weightage for jth centre,

$\mathrm{W}$ is the total weightage of all the centres.

Then the Working Population Index is calculated of each centre using the following formula:

$\mathrm{WIj}=\mathrm{Wj} / \mathrm{Wt} \times 100$

Where WIj is the Worker index of $\mathrm{j}$ th Centre,

$\mathrm{Wj}$ is the Working population of $\mathrm{j}$ th centres,

$\mathrm{Wt}$ is the Total working population in the district.

Also the Non - Worker Index of each centre is calculated using the formula:

$\mathrm{NWIj}=\mathrm{NWj} / \mathrm{NWt} \times 100$

Where NWIj is the Non - Worker Index of the jth centre,

$\mathrm{NWj}$ is the Non - Working Population of the jth centre,

NWt is the Total Non - working population of the district.

Finally, the Composite Functional Index Value (CFI) of each centre is calculated taking the average of the above computed values:

$\mathrm{CFI}=(\mathrm{FCI}+\mathrm{WIj}+\mathrm{NWIj}) / 3$

Similar approach with or without slight variations can be adopted for the study also.

\section{Socio - Economic Study}

\subsection{Decadal Variations in Population}

The decadal growth of the population, area and density of Kollam Corporation is shown. It is found to experience a negative growth rate of 3.4 during the decadal period of 2001 to 2011.
Table 1: Decadal Growth of Kollam Corporation

\begin{tabular}{|r|r|r|r|r|}
\hline Year & Population (lakhs) & Decadal Growth Rate & Area Sq. Km & Density Person/sq.km \\
\hline 1971 & 2.43 & & & \\
\hline 1981 & 2.68 & 14.24 & 18.48 & 14502 \\
\hline 1991 & 3.46 & 29.07 & 18.48 & 18723 \\
\hline 2001 & 3.62 & 4.49 & 57.31 & 6317 \\
\hline 2011 & 3.49 & -3.40 & 57.31 & 6090 \\
\hline
\end{tabular}

The ward wise population density distribution according to the 2001 ward divisions is shown below.

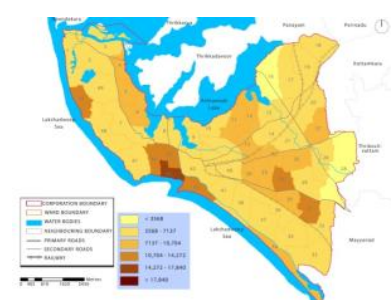

Figure 2: Population Density Distribution according to 2001 Census

The ward wise population density distribution according to the 2011 ward divisions is shown.

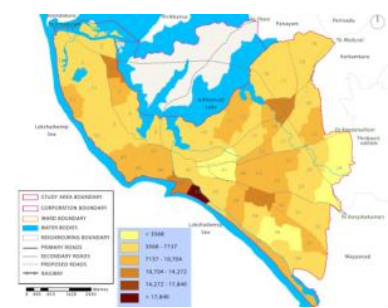

Figure 3: Population Density Distribution according to 2011 Census

On basis of comparison of the population density distribution maps of 2001 and 2011, areas of change are marked.

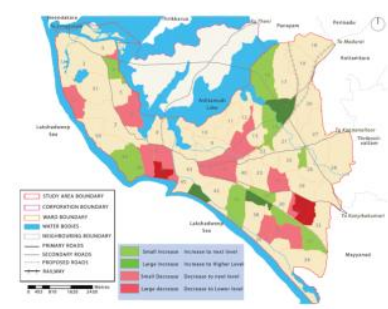

Figure 4: Areas of Change

The core areas are found to mostly decline, whereas the land along the transportation routes are found to be mostly exhibiting increased density, towards the periphery, when considering the eastern part of the core area.

\subsection{Occupational Structure}



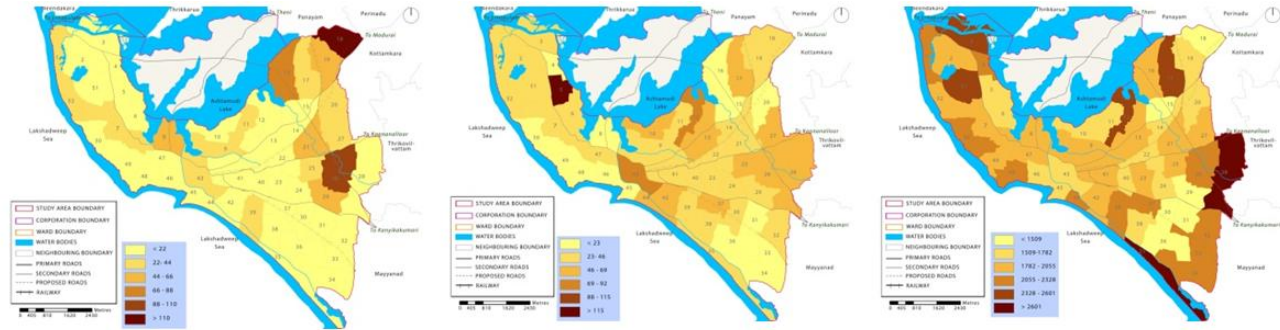

Figure 5: Distribution of concentration of agricultural workers, household industrial workers and other workers respectively

The wards with the highest and medium concentration of agricultural workers have low population density and most of the wards with low concentration of agricultural workers belong to the medium population category. Also, most of the wards with low and medium concentration of household and industrial workers have low population density, and the ward with highest concentration of household industrial. workers have medium population density. Of the wards with low concentration of other workers, most of them belong to the low density category, most of the wards with medium concentration of other workers belong to low and medium density category and most of the wards with high density of other workers belong to the low density category.

Some of the wards with increase in population density have medium or high concentration of agricultural and household industrial workers. Also, most of the wards showing increase in population density have medium density of other workers. Thus we can say that occupational structure has some influence in the distribution and growth of population.

\subsection{Land Use}

Kollam has an uneven development, where the commercial, public \& semi - public, transportation and recreation facilities are mostly concentrated towards the central core area. The population density of these core areas are decreasing and that of the fringes are increasing. Mixed use developments are proposed in these areas as part of GKDP 2031.

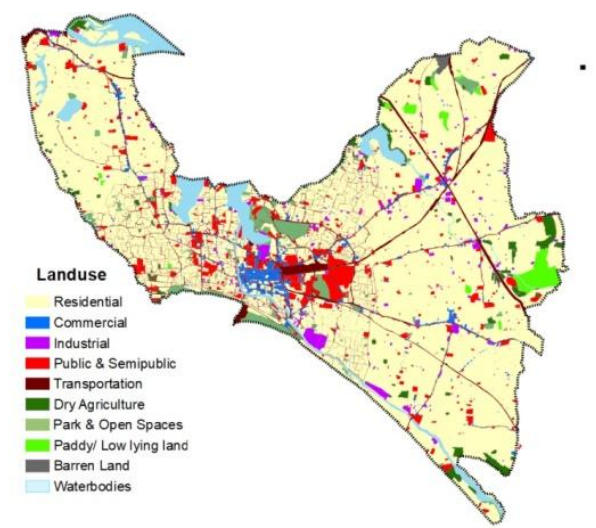

Figure 6: Existing Land use of the Study Area

\subsection{Traffic and Transportation}

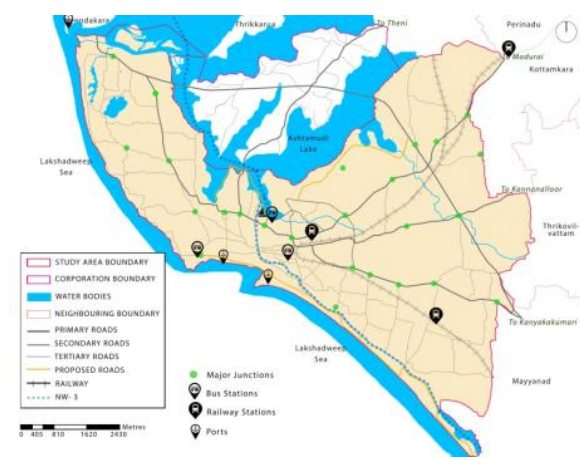

Figure 7: Transportation Map of the study area

The growth and distribution of population with respect to primary roads, major junctions and transit nodes is studied. The growth and decline of population density of wards is influenced up to some extent by the proximity of primary roads. Also, major junctions play an important role in the growth and decline of population densities. Majority of the wards with transit facilities have low population densities. It is also found that wards in the core area are more walkable when compared to the periphery.

\subsection{Major Commercial Nodes}

Majority of the wards with major commercial nodes have experienced decline in population density.

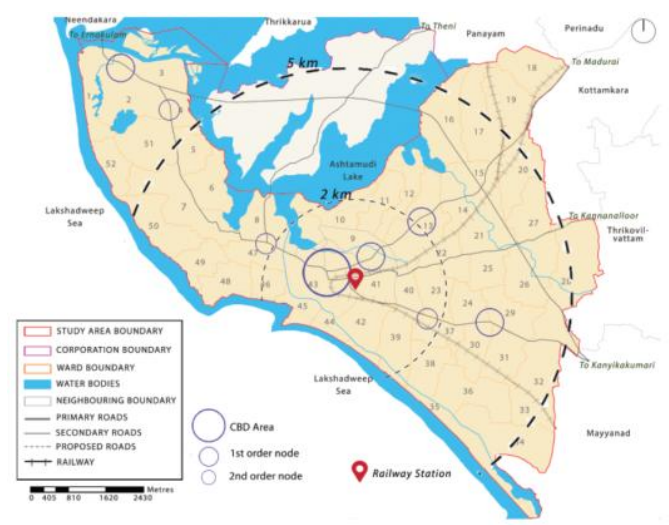

Figure 8: Major Commercial Nodes

\subsection{Major Industrial Nodes}

Majority of wards with proximity to industries have experienced increase in population density. 


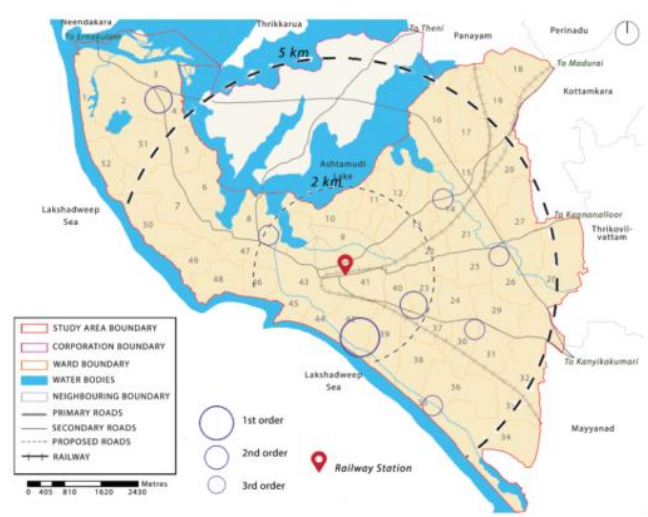

Figure 9: Major Industrial Nodes

\subsection{Housing}

The study area is mainly characterized by single - ownership low - rise houses. But medium rise and high rise apartments are emerging since a few years. The number of houseless families in the city is 609 . The housing density distribution is similar to the population density distribution except for a few changes.

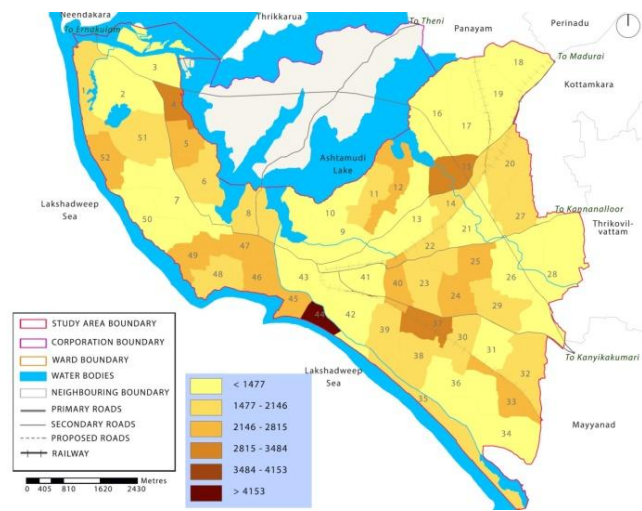

Figure 10: Ward wise household density

In Kollam, the settlement of EWS is seen along the Ashtamudi Lake, ponds and low - lying areas with high risk of flooding but with low land prices. Fishermen colonies along the coast also represent poverty; very few slum - like settlements with high density are also situated in the city centre. [9] There are 102 slums in the study area. The total area of the slums comes to around 0.79 sq. km. Kollam Port Cluster is the most populated slum with a population of 3619 persons and 430 families [9].

Most of the high density population wards and most of the wards with declining population have the presence of slums in it.

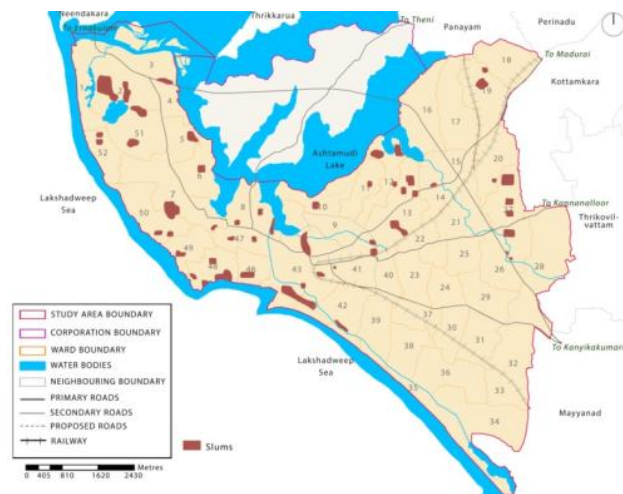

Figure 11: Slums in the study area

Although, high - rise apartments do not play a major role in the growth and distribution of population in Kollam Corporation, a few of the high density wards and population increasing wards have the presence of high - rise apartments.

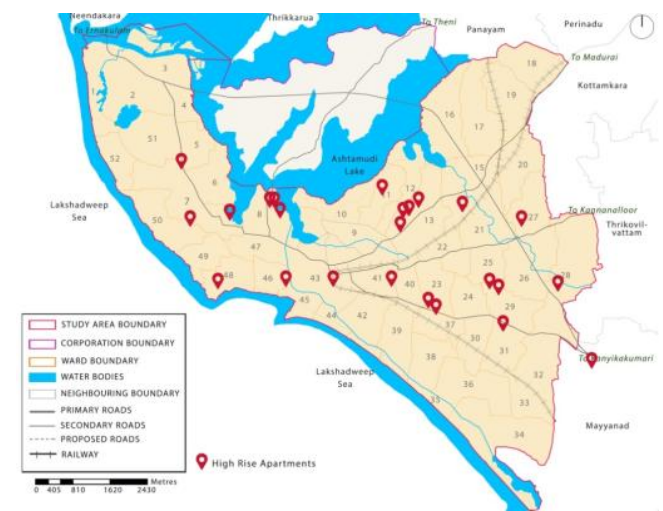

Figure 12: High Rise Apartments

\subsection{Social Infrastructure}

According to the IDDP Report, the educational system of the district is well established at all levels. The major schools and colleges are concentrated and evenly distributed in the corporation area.

As per the IDDP and GKDP 2031, the health infrastructure in Kollam exceeds the standards prescribed in the URDPFI norms. In $\mathrm{KMC}$, at least one hospital with IP facility is accessible to all the wards within $23 \mathrm{~km}$ and is reachable to people within reasonable time. There are 34 PHCs serving the basic health care needs in 52 wards. [9]

As the health and educational facilities are distributed evenly throughout the study area, it is impossible to draw a growth or distribution pattern on the basis of these facilities.

The major recreational areas are Adventure Park, MG Park at Kollam Beach, Ashramom Maidan, Peeranky Maidan, MG Park at Kuravanpalam, Nehru Park, Children's Park at Thevally, Kollam Beach and Thangassery Backwater Tourism. The recreational areas are concentrated towards the core area. 


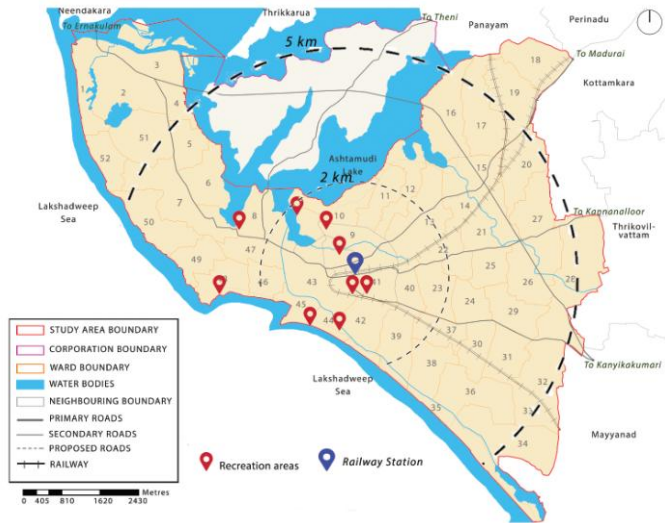

Figure 13: Major Recreational Areas

\subsection{Physical Infrastructure - Water Supply}

18 MLD of water is obtained from Sasthamkotta Lake, whereas 5 MLD of water is obtained from the tube wells. Together, the main water supply system accounts for 23 MLD of water supply. JICA accounts for 3 MLD of water supply. So, the total amount of water supplied is 26 MLD, which means there is $76 \mathrm{lcpd}$ of water available for individual domestic use, while the MoUD recommends 135 lcpd for the same.

The current water demand of the study area, according to CDP - 2041 is 200 lpcd which means the total water demand for the city is $69.8 \mathrm{MLD}$ and the additional water required is 43.8 MLD.

The projected population of the study area for 2041, according to KSUDP DPR, is 408667 , based on the water demand which can be met with the help of existing and proposed water supply services. Therefore, the water demand will be 81.8 MLD.

\subsection{Physical Infrastructure - Sewerage and Sanitation}

At present, there is no organized sewerage disposal facility in Kollam. Individual septic tanks are widely used for sewerage disposal. But no standards or specifications are followed for the operation and maintenance of these. The wastes from these tanks are unscientifically disposed off into the water bodies and low - lying areas, which leads to pollution and degradation of water.

A Sewage network of $38 \mathrm{~km}$ was laid out in the year 1980. The planning of the network had started in 1975. Also, a pumping main was laid out in $3.8 \mathrm{~km}$. But the project was dropped in 1987 due to lack of finance and was never functional. On the basis of topography and development, the areas in KMC were divided into the 3 zones, for the convenience of laying sewer lines.

Table 2: Details of proposed STPs

\begin{tabular}{|l|r|r|c|c|l|}
\hline Zone & $\begin{array}{c}\text { Area } \\
\text { covered, sq. } \\
\mathrm{km}\end{array}$ & Population & $\begin{array}{c}\text { STP } \\
\text { capacity, } \\
\text { MLD }\end{array}$ & $\begin{array}{c}\text { STP area } \\
\text { requirements, } \\
\text { Ha }\end{array}$ & STP Location \\
\hline Zone A: Central MC Area & $18.5 \mathrm{sq} . \mathrm{km}$ & 135,000 & 16 & 1.6 & Kureepuzha \\
\hline Zone B: Western MC Area & $8.0 \mathrm{sq} . \mathrm{km}$ & 50,000 & 8 & 0.8 & Kureepuzha \\
\hline Zone C: Eastern MC Area & $27.8 \mathrm{sq} . \mathrm{km}$ & 140,000 & 20 & 2.0 & $\begin{array}{l}\text { Mulivila or other } \\
\text { suitable location }\end{array}$ \\
\hline
\end{tabular}

In the CDP - 2041 of Kollam Corporation, the sewage generation has been calculated on the basis that $80 \%$ of the water supply will end up as sewerage. Therefore, the sewerage generated in 2041 will be 65.44 MLD.

Under KSUDP, sewage treatment plants are proposed in the 3 locations which are previously mentioned. The plants are supposed to cater to the projected population of 2041. Under Amrut scheme, an STP Plant of 12 MLD capacity is proposed in Kureepuzha, for which the works have started.

\subsection{Physical Infrastructure - Solid Waste Management}

The percentage of households which have access to swm services are $9 \%$, the efficiency of municipal waste collection is $25 \%$ and the extent of waste recovered is $3 \%$. Majority of the households or establishments do not practice waste segregation. There are 260 primary sites and 76 secondary sites for waste collection. Proper waste storage facilities are not provided in most of the sites, they are mostly open sites. The food wastes from door - to - door collection from 5 wards are taken to 9 bio - gas plants located throughout the study area, from where the bio - gas generated is used in surrounding areas. There is a waste disposal facility at Kureepuzha which has a composting plant with capacity 45 MT/ day and a dumping yard. The bio - medical wastes in the study area are collected by IMAGE facility.

The projected waste generation for 2041 is 203 MT/ day. KSUDP has proposed solid waste processing, disposal and treatment facilities at Kureepuzha, targeted for the projected population of 2041. The leachate plant constructed as part of the proposal is never operated due to issues regarding CRZ norms. The project is about to be restarted by solving the issues regarding $\mathrm{CRZ}$ norms.

\subsection{Physical Infrastructure - Storm Water Drainage}

The city has moderate sloping which facilitates natural drainage. The coverage of existing drainage system is only $20 \%$. The storm water drainage in Kollam comprises of primary drains, secondary drains and local drains. The major issues are filling up of low - lying areas and improper maintenance of existing drains. Though there are water logging areas in the city, there are on - going projects proposed by KSUDP and Amrut to solve this issue by constructing new drains and upgrading existing drains.

\subsection{Urban Environment}

Kollam ranked second regarding least concentration of dust particles in the air, out of 123 Indian cities studied by WHO. The Ambient Air Quality of Kollam as per KSUDP is shown below. It can be seen that the levels of sulphur dioxide, oxides of nitrogen and suspended particulate matter are much below the recommended standards. Therefore, according to KSUDP, KMC has a pleasant environment due to lesser number of industries and vehicles [9]. 
Table 3: Ambient Air Quality data for Kollam City

\begin{tabular}{|l|l|l|l|l|l|l|}
\hline \multirow{2}{*}{$\begin{array}{l}\text { Sr. } \\
\text { No. }\end{array}$} & & Standard & \multicolumn{3}{|c|}{ Observed value $(\mu \mathrm{g} / \mathrm{m} 3)$} \\
\cline { 3 - 8 } & & $(\mu \mathrm{g} / \mathrm{m} 3)$ & North & West & South & East \\
\hline 1 & Sulphur dioxide (SO2) & 120 & 19 & 14 & 18 & 26 \\
\hline 2 & Oxides of Nitrogen (NOx) & 120 & 6.5 & 6 & 10.5 & 7.5 \\
\hline 3 & Suspended Particulate Matter (SPM) & 500 & 28.75 & 20.04 & 42.5 & 82.45 \\
\hline
\end{tabular}

The study area is vulnerable to flood and erosions. Areas are more vulnerable towards the periphery.

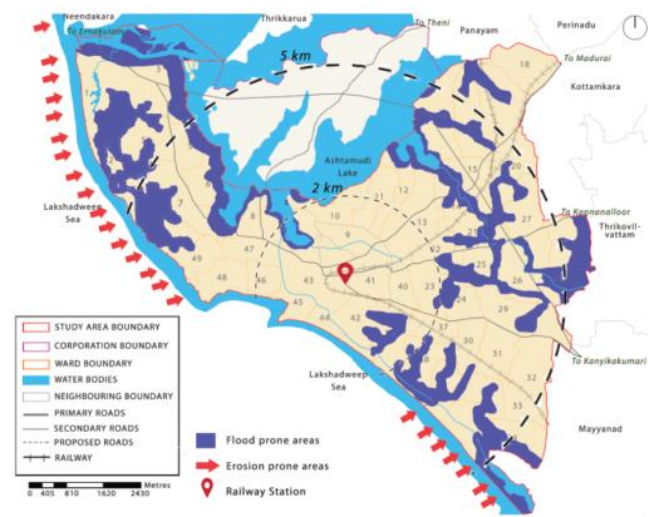

Figure 14: Disaster Vulnerability map of the study area

\section{Holding Capacity}

One of the definitions of holding capacity is that it is the population size that is constrained by whatever resource is in the shortest supply. The population projections in the reports of CDP and KSUDP of KMC are based on the water supply, which has certain shortages in the study area. Therefore, water supply can be taken as a parameter for deciding holding capacity. The projected population and density according to water supply, for the year 2041 is 4, 08, 667 and 7024 persons/sq. $\mathrm{km}$ respectively. The additional population is 59, 649. All the other physical infrastructure facilities such as sewerage and sanitation, storm water drainage and solid waste management are planned for this projected population.

\section{Settlement Hierarchy}

It is a way of arranging the settlements in an area in order of importance based on size, population or the services they provide. In the study, it can be useful in determining the hierarchy of wards for urban compaction. Composite Functionality Index method is usually used to analyse settlement hierarchy. The settlements are to be categorized into hierarchical groups based on the CFI values.

\subsection{Selection of Parameters}

In order, to find the settlement hierarchy for urban compaction, certain parameters have been selected with reference to the sustainability goals and the population trends of the study area:

\subsubsection{Vacant Land}

Vacant land is an important parameter as it is required to develop additional housing and infrastructure for the projected population. The wards with high and medium levels of vacant lands are selected.

\subsubsection{Population density}

The high density wards would be less apt for urban compaction. The low density wards are selected.

\subsubsection{Housing}

Wards with adequate housing can be found out using the average household size of 4.3. Wards with no adequate housing will be lesser opted for urban compaction. There are 11 wards with no adequate housing.

\subsubsection{Social Infrastructure Facilities}

Since educational and health facilities are distributed evenly within the area, they can be excluded as parameters. But, recreation areas can be considered as parameters as they are limited to certain wards.

\subsubsection{Transportation Facilities}

Proximity to major transit nodes and major junctions can be beneficial for urban compaction. Another parameter is walkability of the wards.

\subsubsection{Commercial Facilities}

Proximity to major commercial nodes can be beneficial for urban compaction. There are 17 wards identified with proximity to commercial facilities.

\subsubsection{Vulnerability to Disasters}

The study area is vulnerable to disasters such as floods and sea - erosion. Therefore, less vulnerability to these disasters can be considered as a parameter.

\subsubsection{Air Pollution}

Air pollution is becoming a rising concern for compact cities. The wards with presence of industries are more prone to air pollution.

\subsubsection{Absence of Slums:}

Absence of slums also can be considered as a parameter, because slums reflect lesser living standards in terms of social, economic and environmental aspects.

\subsubsection{Working Population}

Since 'decent work and economic growth' is a criteria for sustainable development, working population is also considered as a parameter. Most are wards with medium and high working population except 9 wards.

\subsection{Calculating Composite Functionality Index}

\subsubsection{Assigning weightage to each parameter}

Weightage of each parameter is calculated by the formula: $\mathrm{Wi}=\mathrm{N} / \mathrm{Fi}$,

Where Wi is the Weightage of ith parameter,

$\mathrm{N}$ is the total number of wards,

$\mathrm{Fi}$ is the number of wards with that parameter. 
Table 4: Calculation of Weightage of each Parameter

\begin{tabular}{|c|c|c|c|}
\hline Sl.no: & Parameters & $\begin{array}{c}\text { No: of wards } \\
\text { with } \\
\text { parameter - } \\
\text { Fi }\end{array}$ & $\begin{array}{c}\text { Weightage } \\
-\mathbf{W i}=\mathbf{5 2} / \mathbf{F i}\end{array}$ \\
\hline 1. & Vacant Land & 21 & 2.476 \\
\hline 2. & Low population density & 28 & 1.857 \\
\hline 3. & Adequate housing & 41 & 1.268 \\
\hline 4. & Recreational Areas & 6 & 8.667 \\
\hline 5. & Major transit nodes & 8 & 6.500 \\
\hline 6. & Major Junctions & 37 & 1.405 \\
\hline 7. & High walkability & 7 & 7.429 \\
\hline 8. & Commercial Nodes & 17 & 3.059 \\
\hline 9. & Less vulnerability to disasters & 14 & 3.714 \\
\hline 10. & Less Air Pollution & 31 & 1.677 \\
\hline 11. & Absence of Slums & 24 & 2.167 \\
\hline 12. & Working population & 43 & 1.209 \\
\hline
\end{tabular}

10.2.2 Calculating Functional Centrality Index of each ward

Functional Centrality Index is calculated by the formula: $F C I=\sum_{i}^{n} \frac{W i j}{W} \times 100$

Where FCI is the Functional Centrality Index,

Wij is the Weightage for jth ward,

$\mathrm{W}$ is the Total Weightage of all the wards.

\subsubsection{Calculating Functional Centrality Index}

Table 5: Calculating FCI of each ward

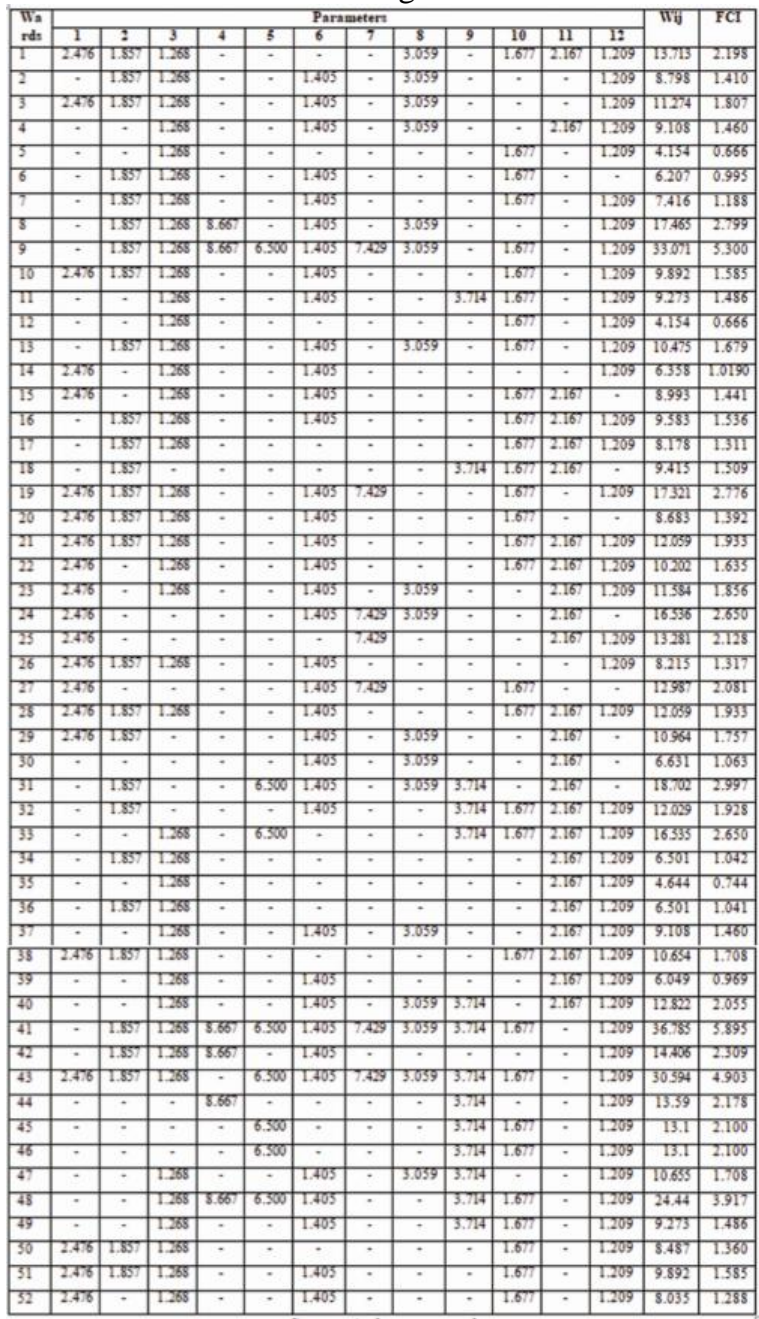

Since there are no other indices, FCI can be considered as the Composite Functionality Index

\subsection{Assigning hierarchical order to each wards based on CFI}

The first order wards will be the most apt for urban compaction, second order will be lesser preferable and the fourth order will be the least apt.

Table 6: Assigning of order

\begin{tabular}{|c|c|c|c|c|c|}
\hline Wards & $\begin{array}{l}\text { Composite } \\
\text { Functional } \\
\text { Index- CFI }\end{array}$ & $\begin{array}{c}\text { Hierarchy } \\
\text { Order }\end{array}$ & Wards & $\begin{array}{l}\text { Composite } \\
\text { Functional } \\
\text { Index- CFI }\end{array}$ & $\begin{array}{c}\text { Hierarchy } \\
\text { Order }\end{array}$ \\
\hline 1 & 2.198 & III & 27 & 2.081 & III \\
\hline 2 & 1.410 & IV & 28 & 1.933 & IV \\
\hline 3 & 1.807 & IV & 29 & 1.757 & IV \\
\hline 4 & 1.460 & IV & 30 & 1.063 & IV \\
\hline 5 & 0.666 & IV & 31 & 2.997 & III \\
\hline 6 & 0.995 & IV & 32 & 1.928 & IV \\
\hline 7 & 1.188 & IV & 33 & 2.650 & III \\
\hline 8 & 2.799 & III & 34 & 1.042 & IV \\
\hline 9 & 5.300 & I & 35 & 0.744 & IV \\
\hline 10 & 1.585 & IV & 36 & 1.041 & IV \\
\hline 11 & 1.486 & IV & 37 & 1.460 & IV \\
\hline 12 & 0.666 & IV & 38 & 1.708 & IV \\
\hline 13 & 1.679 & IV & 39 & 0.969 & IV \\
\hline 14 & 1.0190 & IV & 40 & 2.055 & III \\
\hline 15 & 1.441 & IV & 41 & 5.895 & I \\
\hline 16 & 1.536 & IV & 42 & 2.309 & III \\
\hline 17 & 1.311 & IV & 43 & 4.903 & I \\
\hline 18 & 1.509 & IV & 44 & 2.178 & III \\
\hline 19 & 2.776 & III & 45 & 2.100 & III \\
\hline 20 & 1.392 & IV & 46 & 2.100 & III \\
\hline 21 & 1.933 & IV & 47 & 1.708 & IV \\
\hline 22 & 1.635 & IV & 48 & 3.917 & II \\
\hline 23 & 1.856 & IV & 49 & 1.486 & IV \\
\hline 24 & 2.650 & III & 50 & 1.360 & IV \\
\hline 25 & 2.128 & III & 51 & 1.585 & IV \\
\hline 26 & 1.317 & IV & 52 & 1.288 & IV \\
\hline
\end{tabular}

\section{Analyzed Character}

\subsection{First Order Wards}

- The first order wards are 9,41 and 43.

- Though the 9th and 41 st ward have low levels of vacant land, 43rd ward has medium level of vacant land.

- All the 3 wards have low population density.

- The health and educational facilities are evenly distributed the 3 wards.

- The recreational areas are present in ward 9 and 41 , but not 43.

- Transit nodes are present in the 3 wards: KSRTC Bus Stand in ward 9, Railway Station in ward 41 and Private Bus Stand in ward 43.

- Also major junctions are present in all the wards.

- These are also wards with high walkability.

- Major commercial nodes are present in the 3 wards. 
- These are also wards with adequate housing.

- Though wards 41 and 43 are less vulnerable to disasters, parts of ward 9 are vulnerable.

- These wards also have less proximity to industries, reducing air pollution.

- But all the wards have presence of slums.

- The percentage of working population in ward 9 is medium, whereas the percentage of working population in wards 41 and 43 are high.

\subsection{Second Order Wards}

- Ward 48 is the only ward coming under this category.

- The level of vacant land in this ward is low.

- The level of population density is medium.

- Health, educational and recreational facilities are present within the ward.

- The ward has a bus terminal and a major junction.

- But it does not have high walkability.

- There are also no major commercial nodes present in the ward.

- The housing is adequate.

- It is less vulnerable to disasters.

- It also has less proximity to industries.

- But there are slums present in the ward.

- The ward has medium percentage of working population.

\subsection{Third Order Wards:}

- The third wards are $1,8,19,24,25,27,31,33,40,42$, 45 , and 46.

- The level of vacant land in the wards 1, 19, 24, 25 and 27 is medium and the rest of the wards are low.

- The population density in the wards 1, 8, 19, 31 and 42 are low, and the population density in the wards 24,25 , $27,33,40,45$ and 46 is medium.

- Though the health and education facilities are evenly distributed, the recreation facilities are only present in wards 8 and 42 .

- The wards with major transit nodes are wards $31,33,45$ and 46.

- Wards 8, 19, 24, 27, 31, 40 and 42 are the wards with major junctions.

- Wards with high walkability are wards 19, 24, 25 and 27.

- Major commercial nodes are present in wards 1, 8, 24, 31 and 40.

- The wards with adequate housing are $1,8,19,33,40$ and 42.

- The wards with less vulnerability to disasters are 19,27 , 33, 45 and 46.

- The wards with lesser proximity to industries are 1, 19, 27, 33, 45 and 46.

- The wards with absence of slums are 1, 24, 25, 31, 33 and 40.

- Also, the wards 1, 8, 19, 25, 33, 40, 42, 45 and 46 have medium or high percentage of working population.

\section{Strategies}

Mixed Used Developments: Mixed use developments can be used to incorporate infrastructure facilities in the wards that lack them.

Land Pooling: Land Pooling can be used as an efficient tool here to develop high density housing and infrastructure.

Transferrable Development Rights: TDR is another mechanism to facilitate the speedy acquisition of land for developing infrastructure. It also can be highly beneficial for the realization of urban compaction.

New Housing Projects: New housing projects which are high - density need to be planned in the proposed areas for compaction.

Affordable Housing: Affordable housing is important to reduce the houseless population and the formation of further slums in the area.

Imposition of Vacant Land Tax: Increased tax rates should be imposed for privately - owned vacant lands to discourage owning vacant lands, so that the vacant lands can be acquired by the government and used for infrastructure development.

Effective Utilization of Land: Effective utilization of existing FAR is important to minimize the wastage of land and to provide high - density developments. Adaptive reuse and mixed use developments are commonly used mechanisms to obtain effective land use.

Slum Improvement: The city has 102 slums. Proper slum improvement activities must be carried out to reduce the negative impacts of slums.

Even distribution of commercial land uses: The infrastructure facilities such as commercial and other public uses except educational and health are concentrated towards the core area. If they are evenly distributed throughout the study area, more high density housing could be developed.

Increasing Walkability: The walkability of major junctions needs to be improved to enhance urban compaction. It will help in reducing the use of vehicles.

Common Green Spaces: Green Spaces are to be provided at community and neighborhood levels to reduce the provision of it in individual plots.

Planned Industrial Development: An integrated development for industries are to be brought about to reduce the spread of pollution and for effective utilization of infrastructure.37.7 acres of land at Mundakkal is already being developed as an industrial site.

Restriction of Construction along the Highways: Proper regulations are required for the construction activities along the highways, to reduce ribbon sprawl. 
Urban Edge: An urban edge or containment boundary should be provided around the corporation area, so that most infrastructure provisions are limited after the boundary.

\section{Conclusion}

Urban compaction is an effective tool to curb sprawl and is being used world - wide for the purpose of the same. In Kerala it can be used as a mechanism to control the settlement character of rural - urban continuum. But urban compaction should be planned carefully incorporating sustainability measures and the type of development in the area. It also should be made sure that the adequate infrastructure facilities are available for the projected population in the compacted areas. The limitation in the study is that ward - wise density could not be projected so as to plan out the low - rise, medium - rise and high - rise settlements.

\section{References}

[1] (2014). Perspective Plan 2030 - Kerala.

[2] (2012). State Urbanization Report - Kerala.

[3] (n. d.). Master Plan for Kozhikode Urban Area - 2035

[4] (2012). Thiruvananthapuram Master Plan (Draft

[5] (n. d.). Retrieved from https: //www.sciencedirect. com/topics/social - sciences/urban - sprawl

[6] (n. d.). Retrieved from https: //books. google. co. in

[7] Arathy Gopal, S. N. (2014). An Approach for Analyzing Prospects of Urban Compaction in Indian Cities. Journal of Civil Engineering and Environmental Technology

[8] Khan, N. (2020, April). Mapping Socio - Economic Diversity of Kollam, India. researchgate.

[9] (2014). City Development Plan for Kollam, 2041.

[10] (n. d.). Kerala Sustainable Urban Development Project - Kollam.

[11] (n. d.). District Census Handbook 2011 - Kollam.

[12] Spatial Analysis Wing, T. P. (n. d.). Maps and Data.

[13] (n. d.). Greater Kollam Development Plan - 2031.

[14] (2009). Integrated District Development Plan Kollam.

[15] Mplan, T. (n. d.). Tourism Master Plan for Ashtamudi.

[16] (n. d.). URDPFI Guidelines.

[17] Sarkar, D. S. (2018). Analysis of Rural Service Centres using Spatial Database Approach - A Case Study of Chandauli District, Uttar Pradesh

\section{Author Profile}

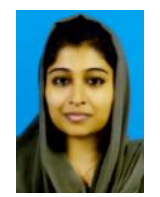

Rahna Abuaker Kovoor received the B. Arch degree from TKM College of Engineering, Kollam in 2014. She is now doing M. Plan at TKM College of Engineering, Kollam (2019 - 2021 batch).

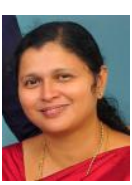

Dr. Sumam Panjikaran is currently working as Professor in Department of Architecture, T. K. M College of Engineering, Kollam. She secured Doctorate in Architecture from School of Architecture and Planning, Chennai, in 2014. After completing her Bachelors degree in Architecture and Masters degree in Housing from College of Engineering, Thiruvanthapuram, She joined TKMCE in 1992. Her favorite topics of interests are Church Architecture, Housing and Sustainable Architecture. 